\title{
Future evolution of automated demand response system in smart grid for low-carbon economy
}

\author{
Huaguang YAN, Bin LI, Songsong CHEN ( $ه)$, \\ Ming ZHONG, Dezhi LI, Limin JIANG,
} Guixiong HE

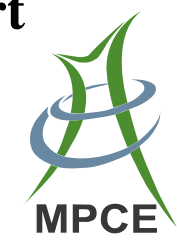

\begin{abstract}
Smart grid construction is an important carrier and an effective way to promote the development of lowcarbon economy. Demand response (DR) is commonly regarded as an important core technology in smart grid field, and it reflects the flexible and interactive features of the core business in smart electricity. It is the developing direction of automated demand response (ADR) technology, and its main features are the standardization of information exchange, together with the intelligence of decision-making and the automation of implementations. ADR technology can improve the efficiency of the whole power system and enhance the ability to accept new energy sources. This paper analyzes the role of demand response in improving efficiency and low-carbon energy saving power systems. The automated demand response system architecture is investigated, and the ADR roadmap of commercial/industrial and residential customer is proposed. The key technologies for ADR system are analyzed, including demand response strategy, information exchanging model, measurement and verification techniques, and multi-agent scheduling techniques. To ensure the interoperability between the grid side and the user side, the ADR business in smart grid user interface standards is concluded to support further demand side management project.
\end{abstract}

CrossCheck date: 11 December 2014

Received: 19 October 2014/Accepted: 12 January 2015/Published online: 3 February 2015

(C) The Author(s) 2015. This article is published with open access at Springerlink.com

H. YAN, S. CHEN, M. ZHONG, D. LI, L. JIANG, G. HE, China

Electric Power Research Institute, Beijing 100192, China

$(\bowtie)$ e-mail: chensongsong2010@163.com

B. LI, School of Electric and Electronic Engineering, North

China Electric Power University, Beijing 102206, China
Keywords Demand response, Information model, System architecture, Load shifting

\section{Introduction}

The smart grid user interface (SGUI) project committee of IEC PC118 was established in 2011, whose secretariat was located in China. SGUI project committee is mainly responsible for the interaction standard between the user side and the grid side. Lawrence Berkeley National Laboratory led the development of open automated demand response (OpenADR) specification to guide and regulate the implementation of demand response. Demand response is an important demand-side management technique $[1,2]$. The user who participates DR program will change their energy consumption pattern in response to the price or incentives signals, and thus optimal allocation of the whole power system can be achieved [3]. Development of smart grid provides strong technical support for further DR implementation, the role of demand response has been extended to expand the access of distributed energy resources and energy storage device. The system peaking load shifting capability can be greatly improved and the user capacity can be considered as a candidate for power system dispatching [4].

Currently, there are several organizations that carry out the smart grid user interface standardization work, including traditional Technical Committee (TC) of the grid side (IEC-TC57 WG21), and TC of the user side (BACnet, $\mathrm{KNX}$ ). Some industrial alliances also set up relevant working groups or revise existing specifications to adapt to the rapid development of building automation and home automation systems. Recently, standard progress shows great interest on the aspects of information exchange between the grid side and the user side [5, 6, 7]. In addition, 
a number of newly established regional organizations (such as German EEbus) focused on the standardization work in this area [8].

While some demand response strategies are implemented by artificial approach, the automated demand response can dynamically adjust load according real-time information of price or incentive signals [9]. Automated demand response will not involve any human interventions and the user response with preprogrammed demand response strategy. If the users are not willing to accept the customized strategy for specified reduction, the participants can also select the opt-out or override functions [10, 11]. Automated demand response can optimize the allocation of resources in load side, or to improve the load capability for ancillary services, and enhance the ability for peak shaving and valley filling [12]. Some users can participate the DR program through load plastic suppliers (load aggregator), which can be regarded as intermediaries between the user side and grid side. A variety of operators will gain an understanding of the level of control in their participation in DR programs and the pricing or incentive signals from power system $[13,14,15]$.

\section{Role of demand response and low-carbon benefits}

\subsection{Brief background}

According to the statistics of FERC at the end of 2008, the total amount of DR resources in United States reaches $41 \mathrm{GW}$ is about $5.8 \%$ of the peak load. It is about $8 \%$ of American users which are involved in a variety of demand response programs, and penetration of smart metering devices to achieve up $4.7 \%$. In 2010, the capacity of demand response in peak load reduction was increased to $53 \mathrm{GW}$, which is about $6.7 \%$ of the system peak load. It is expected in 2020, if all U.S. electricity users preclude the use of real-time pricing and smart metering devices, demand response resources will reach $188 \mathrm{GW}$ (containing $20 \%$ of the system peak load) [16, 17]. The installed capacity of electric power in China can be reduced about $10^{8} \mathrm{~kW}$, which is more than five times of the installed capacity of three Gorges projects. It is estimated that, but also can save $(0.8 \sim 1) \times 10^{12}$ Yuan investment for electric power system in 2020. It is not only greatly resolving resources, environment and investment pressures, but also brings huge economic, environmental and social benefits [18].

The effectiveness of the demand-side participation in electricity market trading and power system operation will be enormous. However, the benefits are obviously different for different actors [19]. The detail benefits and cost of power consumer, power grid enterprise, generation enterprise, and society are listed in Table 1 . In the demand side bidding market, the computing approach for average cost and benefits of each participant have been presented [20, 21]. The demand side bidding operation will generally reduce peak load and the market clearing price, and thus bringing losses to the generation enterprise. For low-carbon economic environment, virtual power station using solar and wind energy for the base load, while the hydro and biogas are used for the peak load [22, 23]. A novel lowcarbon power system dispatching is proposed to support carbon capture power plant, and the relationship between power output and carbon emission is investigated [24, 25]. In the long term, electricity service provider will make up for losses arising during peak hours by increasing the nonpeak hours bid price. Therefore, the benefit allocation mechanisms of demand response is worthy of study to guarantee the fairness of each participant.

\subsection{Economic benefits of DR Projects}

Demand response is a series of strategies that introduce a demand-side electricity market into price-setting process, and it can be divided into two categories: system-oriented and market-oriented programs [26]. The system-oriented demand response can send reduction or load shifting signal to consumers from the power system operators, and it is usually based on system reliability program [27]. The reduction or load shifting compensation price is determined by the system operators or markets. The market-oriented demand response allows consumers to make direct response to price signals, resulting in the changes of consumer behavior or consumption patterns. Typical DR strategies are integrated into an expert library and the reliable operation can be guaranteed with optimized scheduling. The implementation for commercial buildings and enterprise are shown in Fig. 1. The price is formed from the interaction market mechanisms between the wholesale and retail markets. Whether the system-oriented or market-oriented demand response, it will all serve to improve the elasticity of demand.

The virtual power plant can be regarded as a flexible entity in the whole sale electricity market, and the object of DR program is to reduce the peak hour consumption and the shift demand to offpeak hours [28]. For long-term economic benefits of DR program, it is currently used to avoid peak load capacity cost, but the method has the following three defects: 1) Peak load capacity investment is related with annual peak demand arrangements, but the peak price is not always synchronized with the peak load. During annual peak load period, it is unnecessary to involve demand response. However, during the off-peak period, the price will be influenced by the power supply or system peak emergency event. 2) There is not a certain 
Table 1 Benefit and costs of demand response program

\begin{tabular}{|c|c|c|c|}
\hline Name & Benefit & Cost & Comment \\
\hline Power consumer & $\begin{array}{l}\text { Reduce electricity bills; Incentive } \\
\text { compensation reliability worth }\end{array}$ & $\begin{array}{l}\text { Equipment cost } \\
\text { Enstallation cost } \\
\text { Load transfer cost }\end{array}$ & $\begin{array}{l}\text { Equipment/Installation cost: smart meters and } \\
\text { controlling devices for DR system, including } \\
\text { maintenance cost. } \\
\text { Load transfer costs: user change electricity schedule } \\
\text { during peak load period, and will change planning } \\
\text { in advance (industrial and commercial users) or } \\
\text { change schedule (residential customers). }\end{array}$ \\
\hline Power grid enterprises & $\begin{array}{l}\text { Avoidable capacity cost } \\
\text { Operating cost reduction }\end{array}$ & $\begin{array}{l}\text { Equipment cost } \\
\text { Management cost } \\
\text { Sale loss } \\
\text { Incentive expenses }\end{array}$ & $\begin{array}{l}\text { Equipment cost: dispatching system construction } \\
\text { cost, including intelligent device, electricity } \\
\text { station, fiber channel and other major equipments. } \\
\text { Management cost: staff training and maintenance } \\
\text { costs for professional equipment and management } \\
\text { requirement. }\end{array}$ \\
\hline Generation enterprises & $\begin{array}{l}\text { Avoidable capacity cost } \\
\text { Avoid running cost }\end{array}$ & Sale loss & $\begin{array}{l}\text { Sale loss: reducing consumption due to DR program, } \\
\text { the income will be directly reduced. }\end{array}$ \\
\hline Society & Emission reduction benefit & - & - \\
\hline
\end{tabular}

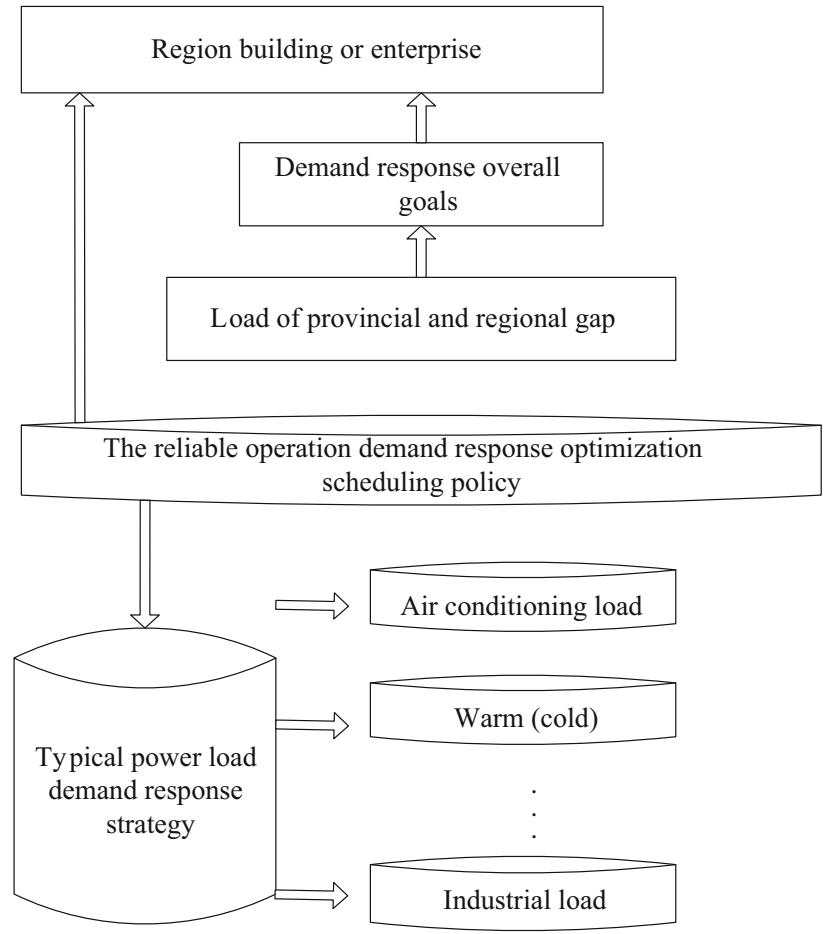

Fig. 1 Demand response strategy library implementation for commercial building or enterprise

relation for fluctuation between the load behavior and the price, the daily demand of all connected consumers and power scheduling approach is commonly regarded as a game with probability distribution. 3) It is controversial about the accuracy of the peak load capacity measurement, as its benchmark value is the load that probably happens but does not happen, so it is difficult to determine the baseline for further user compensation.

\section{Key technology analyses on ADR system implementations}

\subsection{Evolution of ADR system architecture}

Smart grid two-way communications provide necessary channels for demand response service. Information flow interaction in demand response is mainly reflected in the interactive flow of energy supply and demand [29]. DR user in electricity market can obtain the real-time dispatching information through information sharing platform to achieve real-time synchronization between the grid and the virtual network. Users can select either reduce or shift their load to offpeak hours. The dispatching system can make real-time analysis by the collected information from interactive user. Through data mining, it can identify potential business opportunities, and enhance the response capability reliabilities and safety of the power system. OpenADR has proposed a reasonable architecture for further demand response system development, as shown in Fig. 2. It is a quite simple distributed architecture, and can be easily extended to support further service implementations.

Open ADR communication specification provides a complete set of theoretical data model to promote the interests of power companies, power consumers and thirdparty service providers. The demand response event exchange will present price and reliability signals to optimize power resources, and balance energy supply and electricity load [30]. Several electric power services can access the core platform from enterprise bus, and the dispatching command can be delivered through high speed communication network, as shown in Fig. 3. The common 


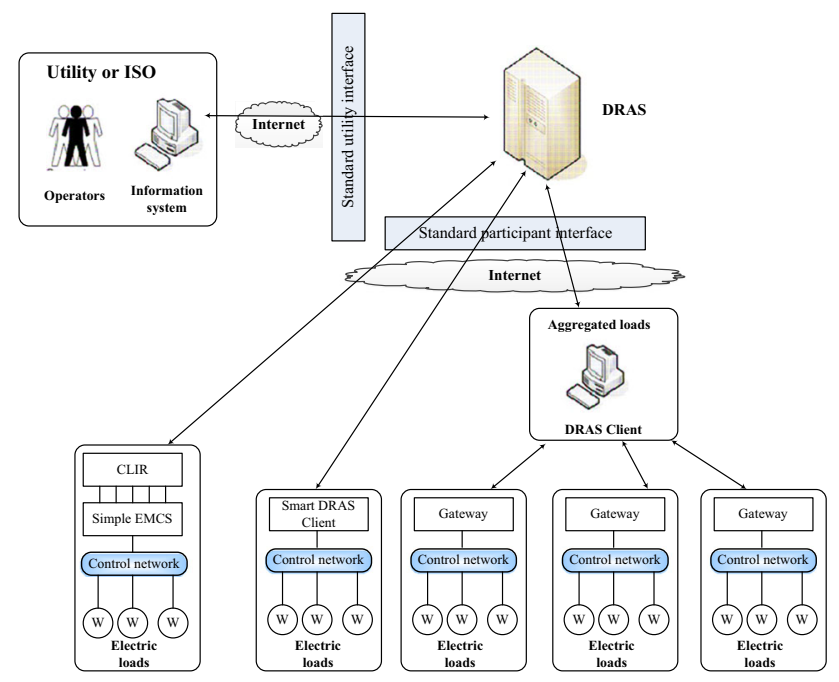

Fig. 2 The prototype of DRAS from OpenADR architecture

communication service interface can be used to provide unified service for different devices, i.e., metering devices, measuring device, and the controlling devices, etc.

\subsection{ADR technology for distributed controlling architecture}

With the development of electric power system, the disadvantages of traditional large power system become more and more obvious. This is due to the fact that the large power system always contains more equipment with less flexibility and convenience, while a higher demand for investment. Nowadays, the distributed energy has a rapid growth in the demand side, thus we need to find a reasonable way for energy consumption for micro-grid solution. Fig. 4 shows the interaction between power company and several distributed users. Typical operating approach of power plane is formulated in [31]. The DER element needs to be connected with a smart controlling device, and there are three typical ways to implement the DR program, i.e., controlling directly for the load, controlling the user (there is an agent to implement the controlling function), and controlling the third-party service provider.

\section{Design of further ADR system to support complex electric service}

\subsection{Demand information interaction model}

The interactions between several parties are essential for demand response application. The biggest difference between smart grid and traditional grid is the smart grid emphasizing interactivity with the user, including business

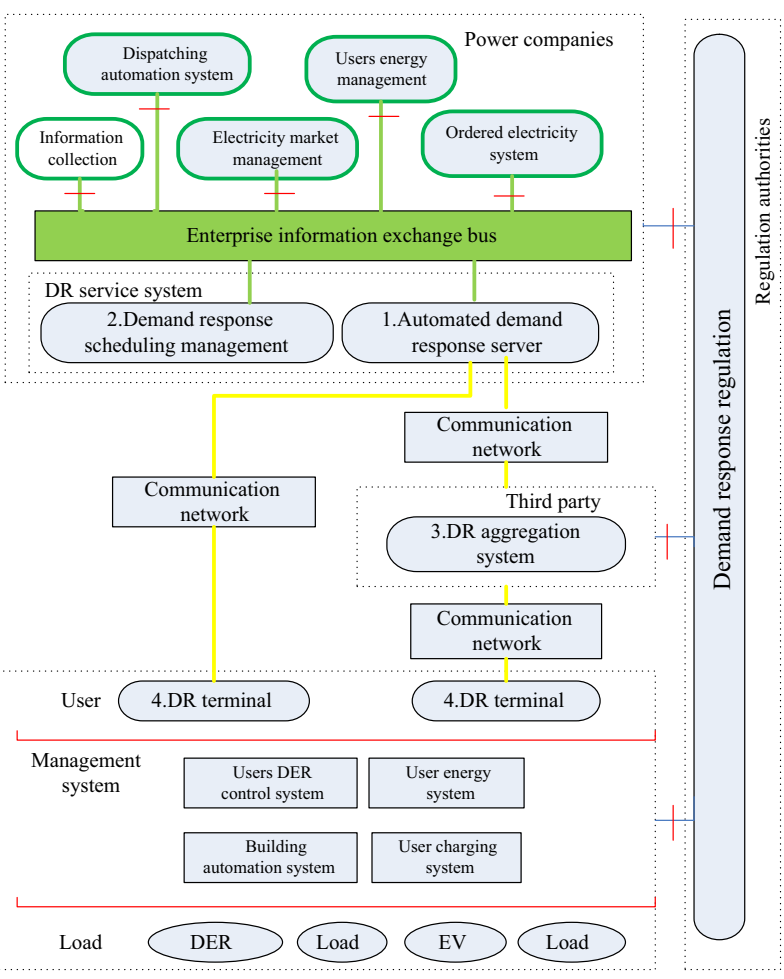

Fig. 3 Common communication service interface design for further electric service access

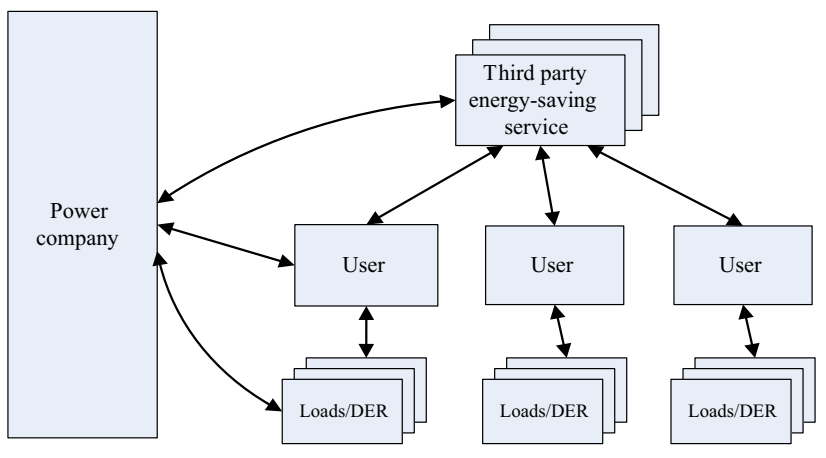

Fig. 4 Demand response resource interaction diagrams

flow, information flow and energy flow interaction. Electric power market demand is a response to the user through a unified network to understand the status of the power grid real-time information sharing platform, to achieve the real time synchronization network. Table 2 lists the detail descriptions between each participant.

1) Promotion of smart meter laid the foundation for interaction between user side and grid side, so as to provide the basis for the development of demand response technologies. Demand response is one of the representative businesses with user interaction, electricity tariff peaks and notification functions for emergency create basic conditions for demand response. Besides, there are other businesses like power quality management with smart 
metering, customer electricity service, and prepaid electricity service.

2) The two-way communication provides the premise condition for large scale demand response applications. The DR information from price server and end-user site are the most critical communication guarantees. The energy flow and information flow are combined together to support complex electricity service. The user receives the current price and takes actions to balance local demand and supply, and all the operation data are recorded for further analysis. After real-time data collections, statistic analysis of the user demand, the business opportunities and potential profit point can be found out through the data mining to achieve an economic, reliable and safe power system.

3) Smart grid energy port technology has gave new vitality to demand response. Demand response is mainly reflected in two-way interaction between power supply and demand which breaks the traditional one-way transport model. In two way interaction program, the user can not only consume electricity, but also supply power to the grid. The technology provides the power of self-management tools and the interface, users can make their choice by defaults, they can also select several electricity customized way and choose reasonable pricing strategy.

4) Smart energy storage will greatly enhance the energy efficiency of new energy sources in DR program. Smart grid operator needs to face energy conservation, and deal with global environmental challenges. Ultimate realization of energy saving goal is inseparable from the user side of the electricity market allocation of resources, in particular user involvement in the demand side. The storage can be distributed, involving the customer to achieve balance between energy source and user load. Smart energy storage technology can promote the user response with high capacity shifting potentials, and it is always expected to be independent and safe to guarantee the emergent energy supply.

5) Energy-efficient technologies provide a support for demand response. Under the background of smart grid, demand response project plays an important role on the stable development of the power industry. Energy-efficient technologies promote the user to change consumption pattern, so as to improve energy efficiency while reducing overall energy consumption. With the energy-efficient device, the user can save unnecessary energy lose, thus reducing the amount of investment. Investors can obtain profit by the new smart grid investment demand, and it can enhance the interaction of demand response participation of all parties.

\subsection{Performance measurement and verification}

Demand Response simulation and evaluation module is important supporting part in DR framework, and it mainly suffers the needs of business decision-making. The tools can provide the basis for the implementation of DR execution performance evaluation

1) The combined effect of demand response verification model

The comprehensive model can be used to simulate the effects of DR implementation, including hierarchical power system operation model and other regional

Table 2 Roles of essential members for DR program participants

\begin{tabular}{|c|c|}
\hline Participant & Description \\
\hline User & $\begin{array}{l}\text { Demand response programs, dynamic pricing or the participants of demand-side bidding, including residential users } \\
\text { commercial users and industrial users, their obligation is to reduce or transfer the load, and thus obtain compensation }\end{array}$ \\
\hline Client & $\begin{array}{l}\text { The user side of the device of directly with suppliers to communicate and participate in demand-side response. A use } \\
\text { can have multiple clients. }\end{array}$ \\
\hline Metering system & Acquisition the user loads, power and switch status, provide a basis for settlement. \\
\hline Aggregation system & $\begin{array}{l}\text { The aggregation system provide demand response services after a large number of users aggregation, connects the } \\
\text { client and server demand response, redistributed the reduce load that automated demand response system released }\end{array}$ \\
\hline Regulator & $\begin{array}{l}\text { Regulators is the makers of demand response programs, dynamic prices or demand side bidding rules, the structures of } \\
\text { the approver rate and the supervisors of implementation process. }\end{array}$ \\
\hline $\begin{array}{l}\text { Third party service } \\
\text { provider }\end{array}$ & $\begin{array}{l}\text { Typically served by systems integrators, energy service companies, energy service companies, response the } \\
\text { development, construction, operation and management of DR monitoring platform. }\end{array}$ \\
\hline DRAS & For publishing dynamic pricing, decomposition releases the load demand and issued DR event notification. \\
\hline Supplier & $\begin{array}{l}\text { The initiator of demand response programs, dynamic pricing or bid the project, typically include utilities, independen } \\
\text { operators or third party cut service providers, provide incentives or compensation for participation user. }\end{array}$ \\
\hline LSE & $\begin{array}{l}\text { Also known as load serving entities (Load-serving Entity, referred LSE), the role is to put together some scattered } \\
\text { resources as a whole to participate in demand response programs, dynamic pricing or demand-side bidding, and } \\
\text { proxy-related business matters. }\end{array}$ \\
\hline
\end{tabular}


substation area. The sale can be obtained from DR contract by electricity authorities. The implementation of the policy response to the effects of relevant party by user demand model demonstration, to provide the expected benefits by scientific performance measurement results of demand response data support.

2) Performance evaluation of user demand response participation

The performance evaluation indicators about user participation in demand response are established, such as load reduction, device number, execution delay, the rebound load, etc. The study of fair and reasonable evaluation about computing approach of DR influence can be used as the basis of user incentives or penalties. It gives a response to the user participation level of the project for evaluation.

3) Comprehensive evaluation of demand response

DR system-level evaluation tools can be used to compute the DR effect for the enterprise, power system, users, and society parties. Both the incentive-based and pricebased DR programs are used to evaluate the detail benefits. Simulation approach can evaluate the influence before large scale demand response program implementations.

\subsection{Multi-agents based scheduling technologies}

As the power companies (i.e., generation, transmission, and distribution) can provide energy for end-user through energy service interface to access to electricity, while users can also provide power to the grid by the energy interface. The energy is transferred from the user-side to the gridside. The power companies mainly aggregate energy flow from the user or the aggregators. The electric power operation enterprise, electricity market companies, electricity providers, and third-party service providers exchange information about the DR program. Electric power operation enterprise is not only responsible for controlling and operations, but also help managing and controlling the user's electrical device, including user energy management systems, user load facility, user storage and distributed energy systems. Electricity market provides a variety of market information to users through information exchange to guide the user's electricity consumption and balance power supply and demand. Electricity service provider's business process supports several type of electricity service for distribution and user. The business includes traditional public electricity service (billing, user management) and the newly appeared end user services, such as energy management and distributed energy generation, etc. Third-party facilitator provides new services and products to meet the new requirement and opportunities brought by smart grid. These new services represent significant new economic growth areas. Load agent or load aggregators, as a large number of small and medium-scale demand response coordination among institutional resources and power grid dispatching centers, can achieve decentralized autonomy within the jurisdiction scope of the load of resources. A number of communication interactions with power companies will enhance power grid reliability and robustness. Acting through the load area, it is effective to manage DR resources that involved in dispatching together with the power supply and demand balance. Load agents can be distribution companies or government entities in the traditional sense. However, the third-party organization of a single type or multiple types can be regarded as an efficient role for the balance. Both the aggregation system and end-devices are necessary roles for load management. Based on historical data or information from other system, it can achieve maximize their profits through strategic offered. To capture the operational behaviors of each device, the scheduling architecture is designed based on load. The agent can be divided into three layers: 1) Scheduling control layer is used to send electricity, resource scheduling requirements and scheduling instructions under a unified decision-making. 2) Acting coordination layer. It can upload strategies together with the resource details and contract information to dispatch center. It is also responsible for the reduction task splitting when the command is received. 3) Local response layer. Electricity end-user uploads scheduling information to local user agent and executes the proxy issued control commands.

According to the internal characteristics of DR resources, various types of DR programs for end users can be taken with different contracts. Agents can offer strategies when receiving price or event from dispatching center according to their own schedule. After the proxy bid successfully, it will guide the end-user to adjust user capacity based on the contract signed before. The agent only compensates for the shifted capacity of end-user by referencing the baseline.

Regional electricity markets in Europe and America are tend to publish daily or hourly energy usage report compared with historical data for each market participants. Bidding in accordance with the operating rules is suitable for different electricity markets, which means that market participants can obtain the historical and biding data for self-learning and optimizing decisions, which are the most important features of a multi-agent system. In the electricity market, the biding operation is always focused on the historical record, i.e., winning quantities, clearing prices. The operator cannot know the exact bidding strategies between each other, if this information can be obtained, the management can be more accurate.

Based on the interactive scheduling mechanism proposed in this paper, it can efficiently control the DR resource to change their consumption pattern or reduce 
unnecessary demands. When the scheduling cost is less than dispatching the same amount of the generations, it is expected that the electricity companies can reduce overall scheduling costs. During the valley period of the electricity, the cost of power company increases because of the discount price that paying for load agent.

The controlling system can be considered as composition of several autonomous and interacting agents. The agents involved in dispatching system will participate load scheduling (at electricity valley or peak period), so that the income distribution can be obtained with reduction or peak shift. Through positive interactions between power company and the load agents, it can promote the user side energy storage, and the electricity load can be efficiently shifted. Table 3 shows several typical DR use cases for different participants in DR program. The intelligent agent will promote new energy resource consumption, and also help to increase the profits of power company. During peak periods, the loads with load shifting capability will transfer or reduce consumption, and thus it reduces the high cost of power company. The distributed controlling framework can be widely applied to large-scale energy consumptions of user without expert driven, high performance server.

The sensitivity of various users in response to the price sensitivity is different, and the load distribution is also different, so it is necessary to make the peak electricity tariff policy for the characteristics of the users. The user agent is divided into three categories, namely industrial users, commercial and residential users, as shown in Fig. 5. They keep in touch with the power company through a user agent, the supplier and government also have a agent for daily transaction process.

\subsection{Case study for intelligent household in DR program}

The energy usage information of home energy device (i.e., water heater, air-conditioner) is collected by an intelligent controller, and the whole energy efficiency can be analyzed at the mater station to achieve energy saving purpose. The detail two-way controlling framework for household appliance is shown in Fig. 6. Through energy management systems and demand-side response platform,

Table 3 Use case design for different participants in DR program

\begin{tabular}{|c|c|c|c|}
\hline Use Case & Events & Description & Participants \\
\hline \multirow[t]{4}{*}{$\begin{array}{l}\text { DR project } \\
\text { configuration }\end{array}$} & Device configuration & $\begin{array}{l}\text { DR project-related infrastructure and personnel } \\
\text { configuration }\end{array}$ & Power supply company \\
\hline & Contract develop & $\begin{array}{l}\text { Grid operation agencies combine multiple interests and } \\
\text { needs of developing DR-related contracts }\end{array}$ & Power supply company \\
\hline & DR capability summary & $\begin{array}{l}\text { Users feedback the DR ability to the grid run } \\
\text { institutions }\end{array}$ & User, power supply company \\
\hline & $\begin{array}{l}\text { Signed a } \\
\text { contractlmodifications }\end{array}$ & $\begin{array}{l}\text { Power grid companies to choose qualified users, } \\
\text { negotiation and contract. }\end{array}$ & User, power supply company \\
\hline \multirow[t]{5}{*}{$\begin{array}{l}\text { DR project } \\
\text { implementation }\end{array}$} & Scheduling instructions & $\begin{array}{l}\text { Grid operation agency sends DR scheduling instructions } \\
\text { to the grid operator }\end{array}$ & Power supply company \\
\hline & Participant query & $\begin{array}{l}\text { Users can query the DR personnel and the load } \\
\text { equipment (air conditioning, water heaters, etc.) }\end{array}$ & User, Power Supply company \\
\hline & $\begin{array}{l}\text { Select/Modify } \\
\text { participant }\end{array}$ & $\begin{array}{l}\text { Choose users that participate in the DR, and timely } \\
\text { changes in the implementation of DR }\end{array}$ & $\begin{array}{l}\text { Power supply company, the grid } \\
\text { operator }\end{array}$ \\
\hline & Load control & $\begin{array}{l}\text { Grid operators carry out corresponding load control } \\
\text { operations, i.e., remote DLC, local DLC, DLC } \\
\text { reminder fee control, peak avoiding DLC, DLC } \\
\text { breakdown }\end{array}$ & $\begin{array}{l}\text { Power supply company, the grid } \\
\text { operator }\end{array}$ \\
\hline & Load monitoring & $\begin{array}{l}\text { The grid operator carry out monitoring and early } \\
\text { warning for device control }\end{array}$ & The grid operator \\
\hline \multirow[t]{3}{*}{$\begin{array}{l}\text { DR project } \\
\text { Settlement }\end{array}$} & Energy metering & $\begin{array}{l}\text { DR resources provide meter data to the grid operator, } \\
\text { the grid operator to provide data to the grid meter run } \\
\text { institutions }\end{array}$ & $\begin{array}{l}\text { Power supply company, the grid } \\
\text { operator }\end{array}$ \\
\hline & $\begin{array}{l}\text { Compensation } \\
\text { implementation }\end{array}$ & $\begin{array}{l}\text { According to the contract, grid operation agency } \\
\text { provides compensation for the user that participate in } \\
\text { the DR }\end{array}$ & Power supply company \\
\hline & Billing inquiry & Users can query settlement amount after the DR & User, power supply company \\
\hline \multirow{2}{*}{$\begin{array}{l}\text { DR project } \\
\text { maintenance }\end{array}$} & DR assessment & Grid operation agencies to assess the DR project & Power supply company \\
\hline & Compensation revise & $\begin{array}{l}\text { Grid operation mechanism combined DR behavior } \\
\text { accordingly revised incentive plan }\end{array}$ & Power supply company \\
\hline
\end{tabular}


the controllers take control strategy to each room through network central controller (gateway) equipment at peak times. The conditioning and refrigeration temperatures are controlled according to actual power usage and preset control strategy. The end-user load changes consumption patterns with predefined strategies to reduce peak electricity load.

The network central controller (gateway) device can make remote control to room air conditioners and other electrical equipment, it can also develop personalized scenario model and control strategies of intelligent editing room through the system to achieve the purpose of energy saving. In order to support data acquisition for different types of energy metering devices, it requires multiple communication protocols interface to achieve multi-energy metering (including single-phase energy meter, three-phase power meter, multi-function power meter), water meter, gas meter, features hot (cold) scale and other parameters at the same time. Data gateway should support multiple metering devices for data acquisition.

During the interaction process between user side and grid side, the communication protocol serves as a

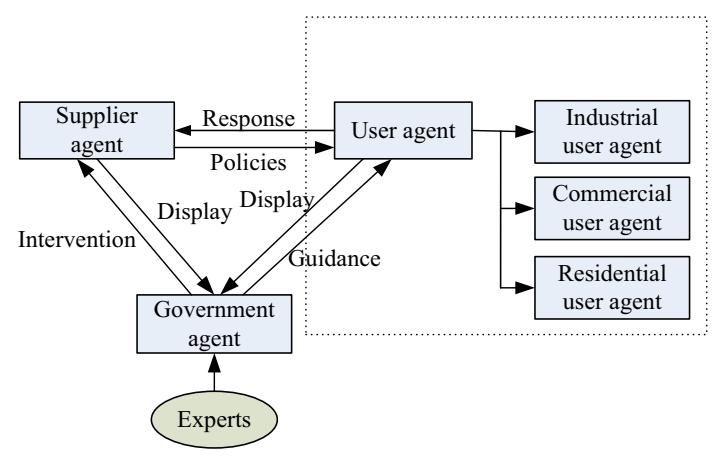

Fig. 5 The multi-agent based scheduling diagram with expert database

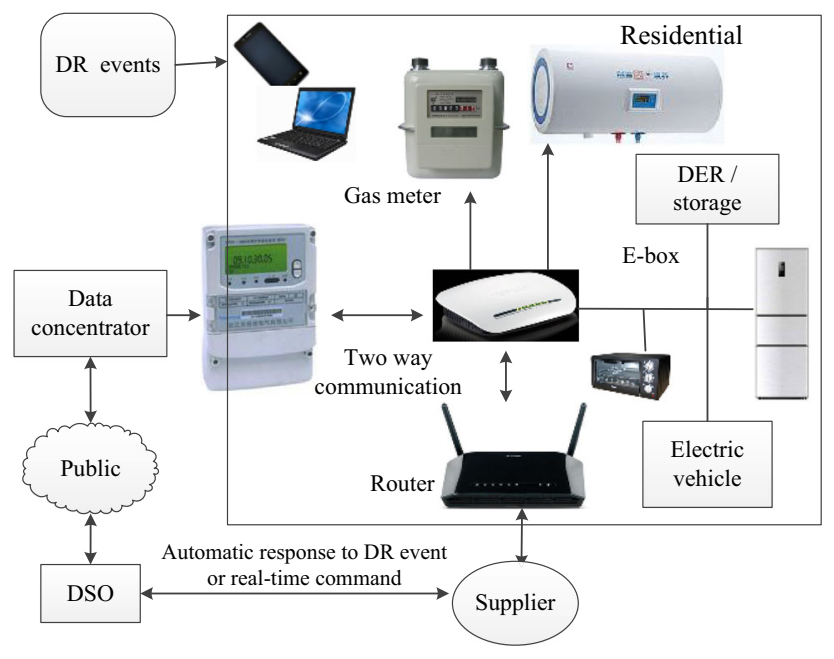

Fig. 6 Implementation for intelligent household

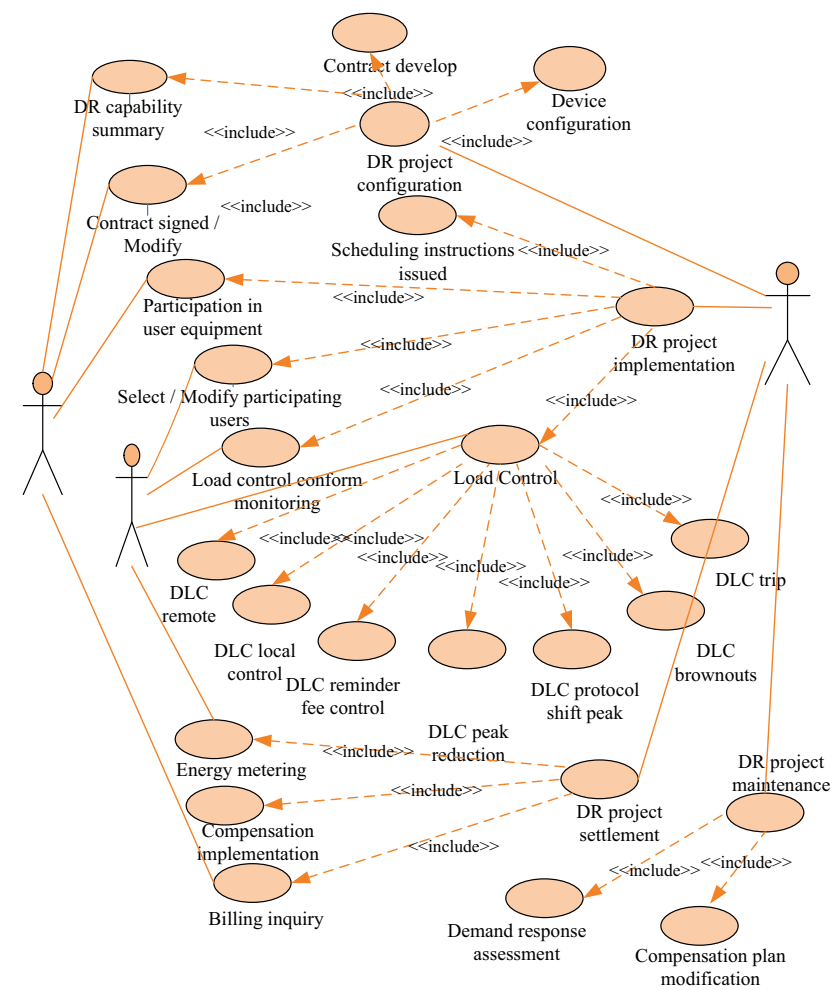

Fig. 7 Use case diagram for multiple roles in ADR system in China

functional interface. The communication primitives for electricity business shall be clearly defined to complete the function and the high-level service calls. For the demand response procedure, it can act as an energy service interface to support smart electricity application. The energy related information shall be transferred through the request and response sequence. As shown in Fig. 7, the power company shall deal with DR events, i.e., initializing the DR, edit/delete DR events, regulating DR participants list, and obtaining the waiting event.

The automatic bidding process receive all current electricity customer bid, and make notifications based on the real-time marking dispatching strategies. The master stations will configure DR project and DR event to every data entity, and monitor behaviors associated with DR program and DR report. The DR signal is generated and distributed to DR controlling agent or DR aggregation system, if the signal is accepted by the third party, it can be sent to the DR energy automation system.

\section{Conclusions}

This paper focuses on standardization and information model between the user side and the grid side. In order to accelerate the industrialization process of smart electricity technologies, the interaction between the master station and several intelligent terminals shall be considered. This 
paper analyzes the role of demand response in promoting efficiency and low-carbon energy saving power systems. Based on the discussion of ADR evolution, the information exchanging model, further interface extension and the detail use case are also presented to support further ADR system implementation. With the designed architecture and key technologies, the main bottleneck for block ADR system is not the aspect of technique anymore. Once the electricity price policy is reformed, the demand response program will be widely carried out in China with good prospect.

Acknowledgments This work was supported by the science and technology projects from State Grid Corporation.

Open Access This article is distributed under the terms of the Creative Commons Attribution License which permits any use, distribution, and reproduction in any medium, provided the original author(s) and the source are credited.

\section{References}

[1] Martinez JA, Dinavahi V, Nehrir MH et al (2011) Tools for analysis and design of distributed resources-Part IV: future trends. IEEE Trans Power Deliv 26(3):1671-1680

[2] Gu Y, Wang DS, Liu CY (2014) DR-cloud: multi-cloud based disaster recovery service. Tsinghua Sci Technol 19(1):13-23

[3] Logenthiran T, Srinivasan D, Khambadkone AM et al (2012) Multiagent system for real-time operation of a microgrid in realtime digital simulator. IEEE Trans Smart Grid 3(2):925-933

[4] Li SH, Zhang D (2014) Developing smart and real-time demand response mechanism for residential energy consumers. In: Proceedings of the 2014 Clemson University power systems conference (PSC'14), Clemson, SC, 11-14 Mar 2014, 5 pp

[5] Nguyen DT, Negnevitsky M, de Groot M (2011) Pool-based demand response exchange - concept and modeling. IEEE Trans Power Syst 26(3):1677-1685

[6] Johal H, Anaparthi K, Black J (2012) Demand response as a strategy to support grid operation in different time scales. In: Proceedings of the 2012 IEEE energy conversion congress and exposition (ECCE'12), Raleigh, NC, 15-20 Sept 2012, pp 1461-1467

[7] Wang YF, Pordanjani IR, Xu W (2011) An event-driven demand response scheme for power system security enhancement. IEEE Trans Smart Grid 2(1):23-29

[8] Wu L, Shahidehpour M, Li T (2007) Stochastic security-constrained unit commitment. IEEE Trans Power Syst 22(2): $800-811$

[9] Ma O, Alkadi N, Cappers P et al (2013) Demand response for ancillary services. IEEE Trans Smart Grid 4(4):1988-1995

[10] Zhou Q, Guan W, Sun W (2012) Impact of demand response contracts on load forecasting in a smart grid environment. In: Proceedings of the 2012 IEEE Power and Energy Society general meeting, San Diego, CA, 22-26 Jul 2012, 4 pp

[11] Xiong G, Chen C, Kishore S, et al (2011) Smart (in-home) power scheduling for demand response on the smart grid. In: Proceedings of the IEEE PES innovative smart grid technologies (ISGT'11), Anaheim, CA, 17-19 Jan 2011, 7 pp

[12] Nguyen DT, Negnevitsky M, de Groot M (2013) Market-based demand response scheduling in a deregulated environment. IEEE Trans Smart Grid 4(4):1948-1956
[13] Kimand TT, Poo HV (2011) Scheduling power consumption with price uncertainty. IEEE Trans Smart Grid 2(3):519-527

[14] Faria P, Vale Z, Morais H (2012) Study of distribution network demand response events in the Portuguese system. In: Proceedings of the 2012 IEEE Power and Energy Society general meeting, San Diego, CA, 22-26 Jul 2012, 8 pp

[15] Nagesh DYR, Krishna JVV, Tulasiram SS (2010) Areal-time architecture for smart energy management. In: Proceedings of the IEEE PES innovative smart grid technologies (ISGT'10), Gaithersburg, MD, 19-21 Jan 2010, 4 pp

[16] Chen C, Wang JH, Kishore S (2014) A distributed direct load control approach for large-scale residential demand response. IEEE Trans Power Syst 29(5):2219-2228

[17] Li HW, Lin XD, Yang HM et al (2014) EPPDR: an efficient privacy-preserving demand response scheme with adaptive key evolution in smart grid. IEEE Trans Parall Distrib Syst 25(8): 2053-2064

[18] Faria P, Vale Z (2011) Demand response in electrical energy supply: an optimal real time pricing approach. Energy 36(8):5374-5384

[19] Medina J, Muller N, Roytelman I (2010) Demand response and distribution grid operations: Opportunities and challenges. IEEE Trans Smart Grid 1(2):193-198

[20] Faria P, Vale Z, Soares J et al (2013) Demand response management in power systems using particle swarm optimization. IEEE Trans Intell Syst 28(4):43-51

[21] Finn P, Fitzpatrick C, Connolly D (2012) Demand side management of electric car charging: benefits for consumer and grid. Energy 42(1):358-363

[22] Pudjianto D, Aunedi M, Djapic P et al (2014) Whole-systems assessment of the value of energy storage in low-carbon electricity systems. IEEE Trans Smart Grid 5(2):1098-1109

[23] Zeng B, Zhang JH, Yang X et al (2014) Integrated planning for transition to low-carbon distribution system with renewable energy generation and demand response. IEEE Trans Power Syst 29(3):1153-1165

[24] Ji Z, Kang CQ, Chen QX et al (2013) Low-carbon power system dispatch incorporating carbon capture power plants. IEEE Trans Power Syst 28(4):4615-4623

[25] Wu YW, Lou SH, Lu SY et al (2011) A model for power system interconnection planning under low-carbon economy with $\mathrm{CO}$ emission constraints. IEEE Trans Sustain Energy 2(3):205-214

[26] Vlachos AG, Biskas PN (2013) Demand response in a real-time balancing market clearing with pay-as-bid pricing. IEEE Trans Smart Grid 4(4):1966-1975

[27] Hopkins MD, Pahwa A, Easton T (2012) Intelligent dispatch for distributed renewable resources. IEEE Trans Smart Grid 3(2): 1047-1054

[28] Luh PB, Michel LD, Friedland P, et al (2010) Load forecasting and demand response. In: Proceedings of the 2010 IEEE Power and Energy Society general meeting, Minneapolis, MN, 25-29 Jul 2010, 3 pp

[29] Sousa T, Morais H, Vale $Z$ et al (2012) Intelligent energy resource management considering vehicle-to-grid: a simulated annealing approach. IEEE Trans Smart Grid 3(1):535-542

[30] Soares J, Canizes B, Lobo C et al (2012) Electric vehicle scenario simulator tool for smart grid operators. Energies 5(6): 1881-1899

[31] Chen QX, KangCQ Xia Q (2010) Modeling flexible operation mechanism of capture power plant and its effects on powersystem operation. IEEE Trans Energy Convers 25(3):853-861

Huaguang YAN was born in ShanDong, P.R.China, in 1977. He is a senior engineering of China Electric Power Research Institute. He is working as the chief engineer of the power consumption and energy 
efficiency research department, and his research interests include Intelligent use of electricity, energy saving and energy efficiency testing.

Bin LI was born in Beijing, P.R.China, in 1983. He is currently a lecturer of School of Electric and Electronic Engineering, in NCEPU. His research interests include Electrical information technology and electric power communications.

Songsong CHEN Corresponding Author, was born in ShanDong, P.R.China, in 1987. He is a engineering of China Electric Power Research Institute. His research interests include Intelligent use of electricity, Information and Telecommunication technology of Intelligent Grid, energy saving and energy efficiency testing.

Ming ZHONG was born in ShanDong, P.R.China, in 1969. He is a engineering of China Electric Power Research Institute. His research interests include Intelligent use of electricity, energy saving and energy efficiency testing.

Dezhi LI was born in HeBei, P.R.China, in 1982. He is a engineering of China Electric Power Research Institute. His research interests include Intelligent use of electricity, energy saving and energy efficiency testing.

Limin JIANG was born in ShanDong, P.R.China, in 1978. He is a engineering of China Electric Power Research Institute. His research interests include Intelligent use of electricity, energy saving and energy efficiency testing.

Guixiong HE was born in HuBei, P.R.China, in 1984. He is a engineering of China Electric Power Research Institute. His research interests include Intelligent use of electricity, energy saving and energy efficiency testing. 